This is an author produced version of a paper published in Urban Forestry \& Urban Greening.

This paper has been peer-reviewed and is proof-corrected, but does not include the journal pagination.

Citation for the published paper:

Sjöman, H., Östberg, J. \& Bühler, O. (2012) Diversity and distribution of the urban tree population in ten major Nordic cities. Urban Forestry \& Urban Greening. Volume: 11, Number: 1, pp 31-39.

http://dx.doi.org/10.1016/j.ufug.2011.09.004.

Access to the published version may require journal subscription.

Published with permission from: Elsevier.

Standard set statement from the publisher:

"NOTICE: this is the author's version of a work that was accepted for publication in Urban Forestry \& Urban Greening. Changes resulting from the publishing process, such as peer review, editing, corrections, structural formatting, and other quality control mechanisms may not be reflected in this document. Changes may have been made to this work since it was submitted for publication. A definitive version was subsequently published in Urban Forestry \& Urban Greening. Volume: 11, Number: 1, pp 3139.http://dx.doi.org/10.1016/j.ufug.2011.09.004.”

Epsilon Open Archive http://epsilon.slu.se 


\title{
Diversity and distribution of the urban tree population in ten major Nordic cities
}

Henrik Sjöman ${ }^{1 *}$, Johan Östberg ${ }^{1}$, Oliver Bühler ${ }^{2}$

${ }^{1}$ Swedish University of Agricultural Sciences, Faculty of Landscape Planning, Horticulture and Agricultural Science, Department of Landscape Management, Design and Construction, Box 66, SE23053 Alnarp, Sweden

${ }^{2}$ Division of Parks and Urban Landscapes, Danish Centre for Forest, Landscape and Planning, Faculty of Life Sciences, University of Copenhagen, Rolighedsvej 23, DK-1958 Frederiksberg, Denmark

*Corresponding author. E-mail addresses: Henrik.Sjoman@slu.se (H. Sjöman), Johan.Ostberg@slu.se (J. Östberg), olb@life.ku.dk (O. Bühler).

Keywords: Invasive species, Native species, Non-native species, Park trees, Species diversity, Street trees

\begin{abstract}
In order to have a healthy and sustainable urban tree population, a high diversity of species and genera is needed. This study examined (1) the diversity and distribution of genera and species of urban trees in the Nordic region; (2) the diversity in different sites of the city, distinguishing between street and park environments; and (3) the presence of native versus non-native tree species in urban environments in the Nordic region. The analysis of tree diversity was based on urban tree databases comprising a total of 190682 trees in 10 Nordic cities - Aarhus and Copenhagen in Denmark; Espoo, Helsinki, Tampere and Turku in Finland; Gothenburg, Malmo and Stockholm in Sweden; and Oslo in Norway. The tree databases for Copenhagen, Espoo, Helsinki, Stockholm and Tampere only record street trees, while the remaining databases also include park trees. Tilia was the most dominant genus in Arhus, Copenhagen, Espoo, Gothenburg, Helsinki, Oslo and Stockholm, while Sorbus was the most dominant in Malmo and Betula in Tampere and Turku. Tilia $\times$ europaea was the most common species, comprising $16.0 \%$ of the total number of tree species. There was a higher proportion of species in parks than in street environments. The number of non-native species was higher than the number of native species in both street and park environments. However, the number of individuals belonging to native species was higher than the number of non-native individuals in all cities and environments except park environments in Arhus. The concluding recommendation from this study regarding greater diversity of genera and species is to exploit local experiences of rare species from local urban tree databases. After appropriate evaluation, urban tree planners can evaluate these rare species in larger numbers for e.g. street environments, where the need is greatest.
\end{abstract}




\section{Introduction}

Urban trees have a number of effects that are beneficial for the quality of life in urban areas. They help reduce the urban heat island intensity (King and Davis, 2007), and thus decrease the need for energy for cooling buildings (Akbari et al., 2001; Maco and McPherson, 2003). Urban trees are capable of reducing storm water runoff and thereby reduce flooding and damage to urban property (McPherson et al., 1997). They also act as noise filters and purify the air through capturing particulate matter, carbon dioxide, ozone and other air pollutants originating from traffic and industrial activities (McPherson et al., 1997; Becket et al., 2000; Nowak et al., 2006). Urban trees also play an important role in recreation for the urban population since they are an important element in green spaces in residential and commercial areas (Tyrvainen et al., 2007). However, the above-mentioned effects are only possible if the urban tree stock is vital and unaffected by pests and diseases.

In order to have a healthy and sustainable urban tree population, a high diversity of species and genera has been proposed as a key solution (e.g. Duhme and Pauleit, 2000; Raupp et al., 2006; Bassuk et al., 2009). The imperative and most frequent argument for high diversity is the recurring outbreaks of diseases and the threat of invasive pests and diseases in the most commonly used tree species (e.g. Sun, 1992; Tello et al., 2005; Raupp et al., 2006). Climate change, with predicted increased average temperatures, more frequent heat waves and periods of drought during summer (IPCC, 2007), is another important issue to take into consideration. Barker (1975) was one of the first to suggest the use of a broad range of species. He recommended that no given species should account for more than $5 \%$ of the total tree population. Smiley et al. (1986) and Miller and Miller (1991) recommend that the maximum share of any species should be less than $10 \%$ of the population. Grey and Deneke (1986) present a similar view, that one species should not amount to more than $10-15 \%$ of the total population. In a refined model, Moll (1989) recommends that no species should exceed $5 \%$ of a city's tree population and that no genus should exceed 10\%. Santamour (1990) extends the recommendations even further to include a recommended maximum use of species and genera from the same family; no species should represent more than $10 \%$, no genus more than $20 \%$ and no family more than $30 \%$ of the population. Such strategic recommendations for species choice are important guidelines for more diverse use of tree species in the urban environment.

In order to analyse the susceptibility of the tree population to outbreaks of pests and diseases and its tolerance to more stressful climates, the composition of the urban tree stock has been studied in many cities (e.g. Sanders, 1981; Jim and Liu, 2001; Pauleit et al., 2002; Sabo et al., 2005; Frank et al., 2006; Raupp et al., 2006; Negandra and Gopal, 2010). However, no such studies have been made exclusively for the Nordic region. Pauleit et al. (2002) carried out a European survey in order to evaluate tree establishment and management practices in 17 countries and nearly 100 towns and cities. In the Nordic region, the study included Denmark (Copenhagen), Finland (Helsinki and Kuopio) and Norway (Oslo). However, the study was limited to newly planted trees in urban areas. In that particular survey Oslo stood out, as $70 \%$ of all newly planted trees in street environments belonged to one clone of Tilia (Tilia xeuropaea 'Pallida'; Pauleit et al., 2002). This lack of diversity clearly indicates the importance of a full review of the tree population in order to avoid future risks. However, since that survey was restricted to newly planted trees and since the data were taken from only a small sample of the total urban area, a complementary study for the Nordic countries is necessary in order to evaluate regional risks for the urban tree population, including both old trees and newly planted trees.

In another study, Sabo et al. (2005) summarised the most common street and park trees in three geographical regions of Europe (Northern, Central and Southern Europe). That survey showed that the range of species was greater in parks than in street environments, indicating that a large number of species are well adapted to the often favourable growth conditions in urban woodlands and parklands, but that finding species able to withstand the challenging conditions in street environments and at other paved sites is much more difficult. In street conditions and other paved environments trees are exposed to a number of stressful elements, e.g. exposure to heat, low air humidity, periods of drought, high lime content and high soil pH, limited soil volume, de-icing salt and other pollutants (Pauleit, 2003; Sieghardt et al., 2005). Even if a city contains high numbers of species in street 
environments, normally a group of a few species typically dominates the urban tree population (Raupp et al., 2006). Urban tree inventories contain valuable, local information about e.g. rare species used in small numbers. If accessible, this information can help increase the number of rarely used species and thereby increase the diversity of the urban tree population.

Another recent issue in planning for greater diversity of tree species and genera is the question of whether non-native species should be used in urban plantations. There have been extensive discussions about the risk of non-native species spreading from the urban environment to natural environments, thereby risking extinction of native species (Parker et al., 1999; Alien Plant Working Group, 2010; Hitchmough, 2011). Chytry' et al. (2008) and Py̌sek et al. (2009) conclude that for a species to successfully escape from cultivation into natural environments and there develop into a potential invasive species, there are two essential factors: propagule pressure (the number of individuals of a species existing in a region) and residence time (how long a species has been cultivated in a region). The longer a species has been in an area, the greater the chances of it escaping. Therefore it is essential to know the number of nonnative species present in an area in order to identify eventual invasion threats at an early stage.

Against this background, the objectives of the present study were three-fold: (1) To obtain basic information on the diversity and distribution of genera and species of urban trees in the Nordic region; (2) to examine the diversity at different sites within cities, distinguishing between street and park environments; and (3) to analyse the presence of native versus non-native tree species in the urban environments of the Nordic region.

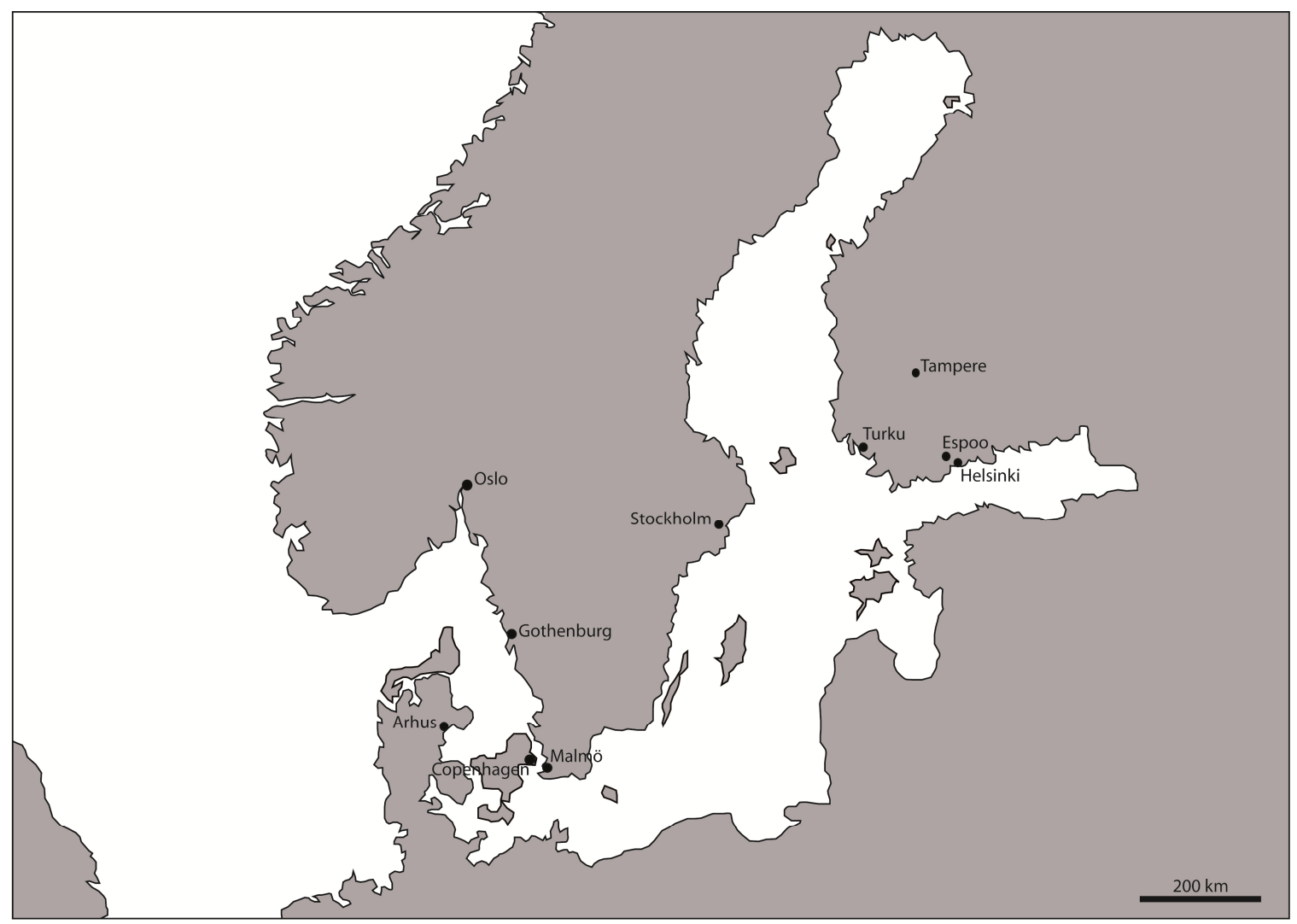

Fig. 1. Map of the 10 Nordic cities studied (illustration by Bjorn Wiström 2010). 


\section{Materials and methods}

The analysis of tree diversity was based on urban tree databases obtained from 10 Nordic cities. A request was sent out to all cities in the Nordic region with more than 200000 inhabitants, in total 10 cities (SCB, 2010; SSB, 2010; STAT, 2010; Statistikbanken, 2010). These cities were Aarhus and Copenhagen in Denmark; Espoo, Helsinki and Tampere in Finland; Gothenburg, Malmo and Stockholm in Sweden; and Bergen and Oslo in Norway (Fig. 1). However, Bergen did not have a developed urban tree database and thereby did not participate in the study. Instead, Turku (176 087 inhabitants) in Finland was selected in order to include 10 major Nordic cities with rather well developed urban tree databases in the study. The selected cities are partly located in the southern maritime region (Aarhus, Copenhagen, Gothenburg, Malmo and Oslo) and partly in the southern continental region (Espoo, Helsinki, Stockholm, Tampere and Turku) of the Nordic region (Sabo et al., 2003).

In the request sent out to the cities, urban tree departments were asked to provide their complete tree database. However, the amount and type of data differed between the cities and only information on the species diversity and distribution was available from all cities in the study. For street environments, Aarhus, Copenhagen, Helsinki, Malmo and Tampere had the almost complete datasets (considered complete in the analyses), while for park environments the amount of data differed between the cities. The databases of the remaining cities are still under development, but had sufficient data to allow analysis (Table 1). In this study, street trees are defined as trees placed in or close to streets or roads and needing special management in order to meet the demands of the street environment.

Accurate taxonomic identification of the species in the study as carried out according to Alden and Ryman (2009). The Nordic Flora (Mossberg and Stenberg, 2003) was used to determine whether the species is native to the region. In the classification of native and non-native species, a hybrid where one of the parents is native to the Nordic region was classified here as native. Trees identified only to genus level were excluded from further analyses in the comparison between native and non native species, as well as in the calculation of species diversity index. In the presentation of genera and species diversity data, species with an occurrence of more than $2 \%$ are presented separately, while the remaining species are grouped under the heading Frequency of less than $2 \%$.

A total of 190682 trees was included in the study (Table 1). The tree databases of Copenhagen, Espoo, Helsinki, Stockholm and Tampere only contain information on street trees, while the remaining databases also include park trees. In the case of Aarhus, Gothenburg and Turku, the total number of trees given is higher than the sum of park and street trees due to missing information regarding the site position of some of the trees (Table 1). In the presentation of tree data from Aarhus, park trees were excluded from the general presentation of genera and species distribution because all park trees except 133 individuals are located in a botanical garden and cemeteries, where the majority of the species are represented by only three individuals or less. Including these trees in the distribution presentation would have given a somewhat skewed picture of the species diversity of Aarhus, since the diversity is located to some particular spots in the city. However, the park trees in Aarhus are included in the presentation of numbers of species in street and park environments in the study, since these trees act as important reference trees for park environments in the region. In order to compare this study with other geographical regions, a species diversity index calculation was made distinguishing between street and park environments (Jim and Liu, 2001). 
Table 1. Total number of trees in the tree databases of the 10 Nordic cities analysed in the study. Trees situated in street and park environments are listed separately.

\begin{tabular}{|c|c|c|c|c|}
\hline City & $\begin{array}{l}\text { Total number } \\
\text { of trees }\end{array}$ & $\begin{array}{l}\text { Total number } \\
\text { of park trees }\end{array}$ & $\begin{array}{l}\text { Total number } \\
\text { of street trees }\end{array}$ & Amount of complete data \\
\hline Arhus & 15539 & 3377 & 12162 & $\begin{array}{l}95 \% \text { of all street trees and } 10-15 \% \text { of park trees have } \\
\text { been inventoried. }\end{array}$ \\
\hline Copenhagen & 18154 & 0 & 18154 & $95 \%$ of street trees have been inventoried. \\
\hline Espoo & 6088 & 0 & 6088 & $30 \%$ of street trees have been inventoried. \\
\hline Gothenburg & 4797 & 1018 & 2154 & The central area of the city has been inventoried \\
\hline Helsinki & 22315 & 0 & 22315 & $\begin{array}{l}90-95 \% \text { of all street trees and } 10-15 \% \text { of park trees } \\
\text { have been inventoried. }\end{array}$ \\
\hline Malmo & 48963 & 27037 & 21926 & $\begin{array}{l}\text { The inventory is complete for all trees that are } \\
\text { maintained by the city's parks department. }\end{array}$ \\
\hline Oslo & 11011 & 7881 & 3130 & The central area of the city has been inventoried \\
\hline Stockholm & 12693 & 0 & 12693 & $\begin{array}{l}\text { All street trees in the central area of the city have been } \\
\text { inventoried, plus } 30 \% \text { of the trees outside the centre. }\end{array}$ \\
\hline Tampere & 20824 & 0 & 20824 & All street trees have been inventoried. \\
\hline Turku & 35095 & 21176 & 13919 & $\begin{array}{l}25-30 \% \text { of the whole urban tree population has been } \\
\text { inventoried. }\end{array}$ \\
\hline
\end{tabular}

\section{Results}

Number and distribution of species

The number of species used differed greatly between the different cities studied. Among cities with complete datasets in street environments, Aarhus had the third highest diversity, with 57 different tree species, whereas Helsinki, which has a colder climate, had 48 different species. The highest diversity based on the urban tree databases was reported for Malmo, with 133 different tree species, followed by Copenhagen (66) and the lowest amount of species was reported for Tampere (27). Within this compilation trees identified only to genus level were excluded.

Analysis of the number of tree genera in all cities studied revealed a clear dominance of Tilia, which accounted for $23.7 \%$ of the total tree population (Table 2). Tilia together with Acer, Betula and Sorbus represented $58.3 \%$ of the total tree stock (Table 2). In terms of the genus distribution of the individual cities, Tilia was the dominant genus in Aarhus, Copenhagen, Espoo, Gothenburg, Helsinki, Oslo and Stockholm, while Sorbus was the dominant genus in Malmo and Betula in Tampere and Turku. The major dominance of Tilia was particularly pronounced in Helsinki, where it accounted for $44.7 \%$ of the total tree population
(Table 2). In Helsinki the two most common genera (Tilia and Acer) represented over half $(57.4 \%)$ the tree population. A situation with two genera representing over half the tree population was also found in Gothenburg, Oslo, Stockholm and Tampere (Table 2).

In terms of species representation in all cities studied, Tilia $\times$ europaea L. was the most common species, with $16.0 \%$ of the total number of tree species. This was followed by Acer platanoides L. (9.2\%), Betula pendula Roth. (9.0\%), Sorbus $\times$ intermedia (Ehrh.) Pers. (4.8\%), Tilia spp. (4.4\%), Sorbus aucuparia L. (3.9\%), and Ulmus glabra Huds. (3.2\%) (Table 3). These seven most common species accounted for more than $50 \%$ of the total tree population in the 10 cities studied. As regards the number of species in the individual cities, Tilia $x$ europaea was the most common species in five of the 10 cities (Copenhagen 23.7\%, Espoo 23\%, Gothenburg 27.1\%, Helsinki 44.3\%; Turku 12.5\%); in Oslo and Stockholm Tilia spp. was the most dominant species $(25.1 \%$ and $25.6 \%$, respectively); in Tampere Betula pendula was the dominant species with $32.1 \%$ of the population, and in Aarhus Sorbus mougeotti Soy.-Will. \& Godr. was the most 
common species, accounting for $11.3 \%$ while Sorbus x intermedia were accounting for $9.1 \%$ in Malmo. In Helsinki and Tampere, only two species accounted for over half the total number of trees, Tilia $x$ europaea and Acer platanoides in Helsinki and Betula pendula and Tilia $x$ europaea in Tampere (Table 3). In contrast, Malmo reported that 12 species accounted for half the tree population and that no single species represented more than $10 \%$ of the total tree stock.

The geographical location of the cities studied was reflected in the use of species. In the three most

\section{Number of species in streets and park environments}

The number of species used differed greatly between the different cities studied. Among cities with complete datasets in street environments, Aarhus had the third highest diversity, with 57 different tree species, whereas Helsinki, which has a colder climate, had 48 different species. The highest diversity based on the urban tree databases was reported for Malmo, with 133 different tree species, followed by Copenhagen (66) and the lowest amount of species was reported for Tampere (27). Within this compilation trees identified only to genus level were excluded.

Analysis of the number of tree genera in all cities studied revealed a clear dominance of Tilia, which accounted for $23.7 \%$ of the total tree population (Table 2). Tilia together with Acer, Betula and Sorbus represented $58.3 \%$ of the total tree stock (Table 2). In terms of the genus distribution of the individual cities, Tilia was the dominant genus in Aarhus, Copenhagen, Espoo, Gothenburg, Helsinki, Oslo and Stockholm, while Sorbus was the dominant genus in Malmo and Betula in Tampere and Turku. The major dominance of Tilia was particularly pronounced in Helsinki, where it accounted for $44.7 \%$ of the total tree population (Table 2). In Helsinki the two most common genera (Tilia and Acer) represented over half $(57.4 \%)$ the tree population. A situation with two genera representing over half the tree population was also found in Gothenburg, Oslo, Stockholm and Tampere (Table 2).

In terms of species representation in all cities studied, Tilia $\times$ europaea L. was the most common species, with $16.0 \%$ of the total number of tree species. This was followed by Acer platanoides L. (9.2\%), Betula pendula Roth. (9.0\%), Sorbus $\times$ southerly cities, Aarhus, Copenhagen and Malmo, species such as Platanus $x$ hispanica Munchh. and Fagus sylvatica L. made up a rather high proportion of the population (Table 3). In contrast, in the more northerly cities of Espoo, Helsinki, Oslo, Stockholm, Tampere and Turku, there was a high proportion of species representative of the boreal and nemoboreal region, such as Alnus glutinosa (L.), Betula pendula, Picea abies (L.) U.Karst., Pinus sylvestris L. and Sorbus aucuparia.

intermedia (Ehrh.) Pers. (4.8\%), Tilia spp. (4.4\%), Sorbus aucuparia L. (3.9\%), and Ulmus glabra Huds. (3.2\%) (Table 3). These seven most common species accounted for more than $50 \%$ of the total tree population in the 10 cities studied. As regards the number of species in the individual cities, Tilia $x$ europaea was the most common species in five of the 10 cities (Copenhagen 23.7\%, Espoo 23\%, Gothenburg 27.1\%, Helsinki 44.3\%; Turku 12.5\%); in Oslo and Stockholm Tilia spp. was the most dominant species $(25.1 \%$ and $25.6 \%$, respectively); in Tampere Betula pendula was the dominant species with $32.1 \%$ of the population, and in Aarhus Sorbus mougeotti Soy.-Will. \& Godr. was the most common species, accounting for $11.3 \%$ while Sorbus $x$ intermedia were accounting for $9.1 \%$ in Malmo. In Helsinki and Tampere, only two species accounted for over half the total number of trees, Tilia $\times$ europaea and Acer platanoides in Helsinki and Betula pendula and Tilia $\times$ europaea in Tampere (Table 3). In contrast, Malmo reported that 12 species accounted for half the tree population and that no single species represented more than $10 \%$ of the total tree stock.

The geographical location of the cities studied was reflected in the use of species. In the three most southerly cities, Aarhus, Copenhagen and Malmo, species such as Platanus $\times$ hispanica Munchh. and Fagus sylvatica $L$. made up a rather high proportion of the population (Table 3 ). In contrast, in the more northerly cities of Espoo, Helsinki, Oslo, Stockholm, Tampere and Turku, there was a high proportion of species representative of the boreal and nemoboreal region, such as Alnus glutinosa (L.), Betula pendula, Picea abies (L.) U.Karst., Pinus sylvestris $L$. and Sorbus aucuparia. 


\begin{tabular}{|c|c|c|c|c|c|c|c|c|c|c|c|}
\hline Genus & $\begin{array}{l}\text { Total in the } 10 \\
\text { cities }\end{array}$ & Arhus & Copenhagen & Espoo & Gothenburg & Helsinki & Malmo & Oslo & Stockholm & Tampere & Turku \\
\hline Acer & $12.1 \%$ & $7.7 \%$ & $11.6 \%$ & $19.8 \%$ & $5.8 \%$ & $12.7 \%$ & $8.7 \%$ & $23.7 \%$ & $21.0 \%$ & $10.3 \%$ & $10.7 \%$ \\
\hline Aesculus & $2.7 \%$ & $6.0 \%$ & $5.4 \%$ & & $3.3 \%$ & & $4.9 \%$ & $5.3 \%$ & $3.0 \%$ & & \\
\hline Alnus & & & & & & & & & & $4.0 \%$ & $3.6 \%$ \\
\hline Betula & $10.9 \%$ & & & $9.4 \%$ & $4.5 \%$ & $11.1 \%$ & $3.0 \%$ & $11.7 \%$ & $8.8 \%$ & $39.1 \%$ & $14.9 \%$ \\
\hline Crataegus & $2.1 \%$ & & $2.4 \%$ & & & $2.1 \%$ & $4.2 \%$ & & $3.1 \%$ & & \\
\hline Fagus & $2.1 \%$ & & & & $3.4 \%$ & & $4.3 \%$ & & & & \\
\hline Fraxinus & $2.8 \%$ & $2.7 \%$ & $7.5 \%$ & & $2.8 \%$ & & $3.9 \%$ & $2.5 \%$ & & & $2.8 \%$ \\
\hline Malus & & $2.3 \%$ & & & & & $2.8 \%$ & & & & $3.5 \%$ \\
\hline Picea & $2.0 \%$ & & & & & & & & & & $8.6 \%$ \\
\hline Pinus & $3.2 \%$ & & & $2.6 \%$ & & & & & $5.1 \%$ & $3.5 \%$ & $9.7 \%$ \\
\hline Populus & $3.4 \%$ & $3.3 \%$ & $2.8 \%$ & $2.9 \%$ & & $2.2 \%$ & $6.1 \%$ & & & & $2.9 \%$ \\
\hline Prunus & $3.9 \%$ & $8.3 \%$ & $2.1 \%$ & & $3.5 \%$ & & $8.7 \%$ & $4.4 \%$ & $5.2 \%$ & & $3.1 \%$ \\
\hline Quercus & $3.9 \%$ & $6.8 \%$ & $4.6 \%$ & $3.2 \%$ & $3.0 \%$ & $3.4 \%$ & $5.4 \%$ & $3.2 \%$ & $2.1 \%$ & & $3.2 \%$ \\
\hline Robinia & & & $3.7 \%$ & & & & & & & & \\
\hline Salix & $2.2 \%$ & $2.0 \%$ & & & & & $3.9 \%$ & & & & $2.9 \%$ \\
\hline Sorbus & $11.6 \%$ & $18.0 \%$ & $8.8 \%$ & $15.9 \%$ & $4.2 \%$ & $7.5 \%$ & $14.0 \%$ & $2.8 \%$ & $11.7 \%$ & $12.7 \%$ & $9.8 \%$ \\
\hline Tilia & $23.7 \%$ & $24.5 \%$ & $34.7 \%$ & $26.9 \%$ & $46.3 \%$ & $44.7 \%$ & $13.3 \%$ & $27.1 \%$ & $31.9 \%$ & $23.7 \%$ & $14.0 \%$ \\
\hline Ulmus & $3.8 \%$ & & & $13.2 \%$ & $8.9 \%$ & $8.5 \%$ & & $8.9 \%$ & & & $5.7 \%$ \\
\hline
\end{tabular}

frequency of less

than $2 \%$ 
Table 3. Proportion of species found in the 10 Nordic cities studied, irrespective of site situation.

\begin{tabular}{|c|c|c|c|c|c|c|c|c|c|c|c|}
\hline Species & $\begin{array}{l}\text { Total in the } 10 \\
\text { cities }\end{array}$ & Arhus & Copenhagen & Espoo & Gothenburg & Helsinki & Malmo & Oslo & Stockholm & Tampere & Turku \\
\hline Acer platanoides & $9.2 \%$ & $10.3 \%$ & $7.2 \%$ & $19.1 \%$ & $2.4 \%$ & $12.6 \%$ & $3.1 \%$ & $18.5 \%$ & $16.3 \%$ & $9.1 \%$ & $10.0 \%$ \\
\hline Acer pseudoplatanus & & $2.5 \%$ & $2.8 \%$ & & & & $2.6 \%$ & $3.9 \%$ & & & \\
\hline Acer spp. & & & & & & & & & $4.1 \%$ & & \\
\hline Aesculus hippocastanum & $2.5 \%$ & $4.0 \%$ & $5.1 \%$ & & $2.6 \%$ & & $4.3 \%$ & $5.2 \%$ & $3.0 \%$ & & \\
\hline Alnus glutinosa & & & & & & & & & & $3.7 \%$ & $3.5 \%$ \\
\hline Betula pendula & $9.0 \%$ & $4.1 \%$ & & $8.9 \%$ & $2.4 \%$ & $10.8 \%$ & $2.5 \%$ & $3.8 \%$ & $6.9 \%$ & $32.1 \%$ & $12.5 \%$ \\
\hline Betula pubescens & & & & & & & & $2.4 \%$ & & & \\
\hline Betula spp. & & & & & & & & $5.6 \%$ & & $6.3 \%$ & \\
\hline Carpinus betulus & & & & & $2.0 \%$ & & $2.1 \%$ & & & & \\
\hline Crataegus spp. & & & & & & & & & $3.0 \%$ & & \\
\hline Fagus sylvatica & & & & & $3.4 \%$ & & $4.3 \%$ & & & & \\
\hline Fraxinus excelsior & $2.3 \%$ & $3.6 \%$ & $6.1 \%$ & & $2.7 \%$ & & $3.0 \%$ & $2.4 \%$ & & & $2.6 \%$ \\
\hline \multicolumn{12}{|l|}{ Fraxinus spp. } \\
\hline Malus hybr. & & $2.0 \%$ & & & & & & & & & \\
\hline Picea abies & & & & & & & & & & & $3.1 \%$ \\
\hline Picea omorika & & & & & & & & & & & $2.8 \%$ \\
\hline Pinus sylvestris & $2.2 \%$ & & & & & & & & $4.9 \%$ & $2.5 \%$ & $8.1 \%$ \\
\hline Platanus $x$ hispanica & $2.1 \%$ & $4.2 \%$ & $11.5 \%$ & & & & $2.9 \%$ & & & & \\
\hline Populus nigra & & & & & & & $2.3 \%$ & & & & \\
\hline Populus tremula & & & & $2.8 \%$ & & & & & & & $2.1 \%$ \\
\hline Prunus avium & & & & & & & $4.7 \%$ & & & & \\
\hline Prunus spp. & & & & & & & & $3.3 \%$ & & & \\
\hline Quercus robur & $2.8 \%$ & $7.9 \%$ & & $3.2 \%$ & $2.1 \%$ & $3.4 \%$ & $3.4 \%$ & & & & $3.2 \%$ \\
\hline
\end{tabular}

Quercus spp. 
Robinia pseudoacacia

\section{Salix alba}

Sorbus aucuparia

Sorbus $x$ intermedia

Sorbus latifolia

Sorbus mougeotti

Tilia cordata

Tilia x europaea

Tilia platyphylla

Tilia spp.

Ulmus glabra

Ulmus minor
$3.3 \%$
$2.3 \%$

$3.7 \%$

$5.7 \%$

$5.0 \%$

$11.3 \%$

$8.0 \%$

$7.3 \%$

$16.0 \%$

$4.4 \%$

$3.2 \%$
$4.8 \%$

$.1 \%$

.0\%

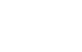

Species with a frequency of $\quad 35.3 \%$ less than $2 \%$

$2.3 \%$

$3.6 \%$

$2.9 \%$

$6.0 \%$

$9.0 \%$

$4.5 \%$

$23.7 \%$

$3.6 \%$

$2.9 \%$
$2.8 \%$

$6.0 \%$

$2.2 \% \quad 5.3 \%$

$23.0 \% \quad 27.1 \%$

$11.7 \%$

$11.3 \% \quad 6.4 \%$

$2.1 \%$
$11.9 \%$

$5.9 \%$

$8.8 \%$

$2.1 \%$

$3.0 \%$

$44.3 \% \quad 8.6 \%$

$2.1 \%$

$25.1 \%$

$25.6 \%$

$8.4 \%$

$8.0 \%$

$5.3 \%$ 
Number of species in streets and park environments The highest number of tree species growing in a street environment was found in Malmo, with 113 species, followed by Turku (74) and Copenhagen (66) (Fig. 2). On comparing the number of species in streets and park environments in the five cities where this subdivision was made, the general conclusion was that there was a higher proportion of species in parks compared with street environments.

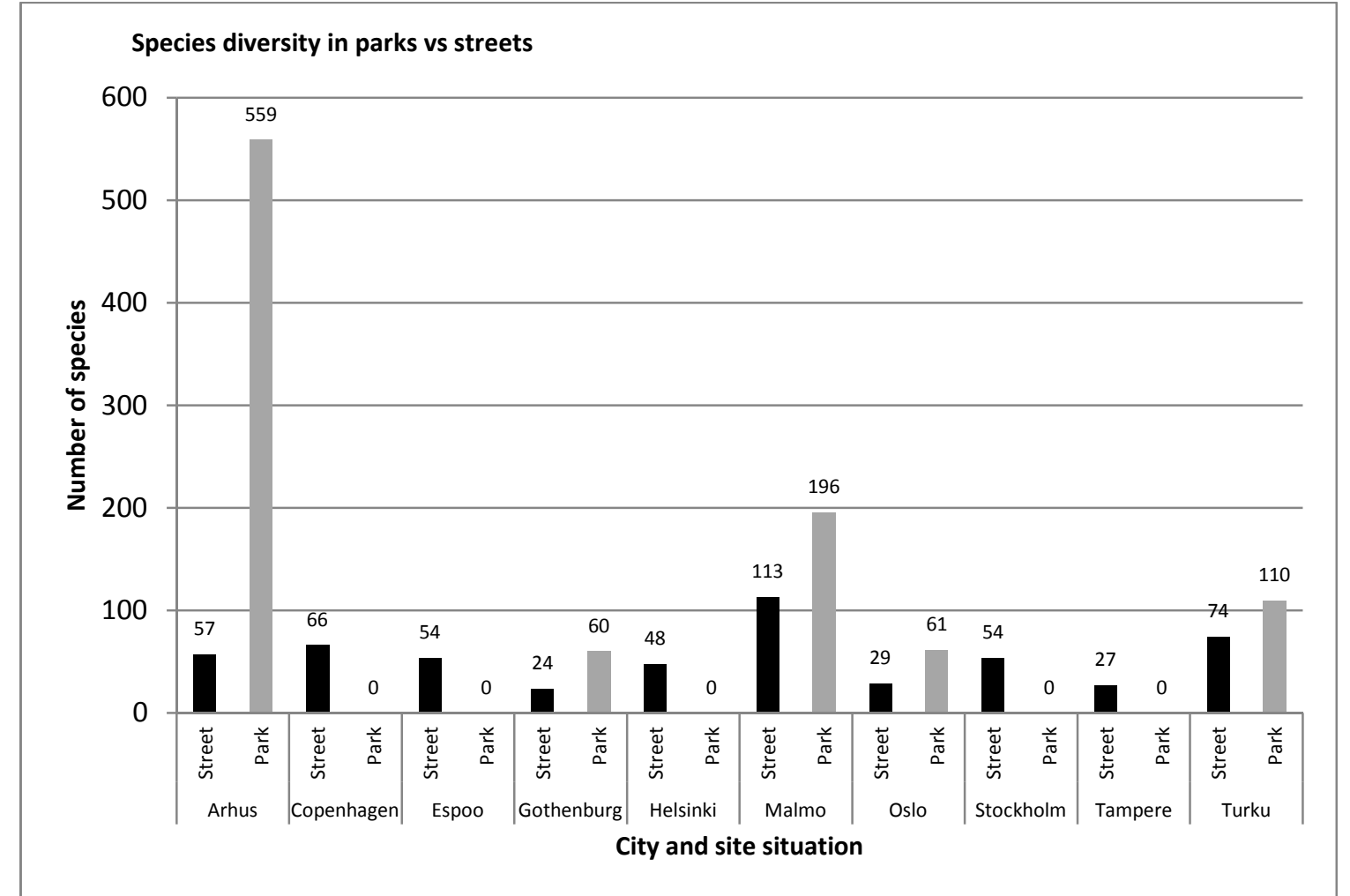

Fig. 2. Distribution of park and street tree species in the 10 Nordic cities studied (no data on park tree species available for Copenhagen, Espoo, Helsinki, Stockholm and Tampere).

Malmo had the highest proportion of species that occurred with a frequency of less than $2 \%$ of the total tree population. In park environments this group comprised $45.1 \%$ of the total tree stock, while in street environments it accounted for $35.9 \%$ of the total population. The second highest distribution of species representing less than $2 \%$ of the total tree population was reported from Turku, with $42.8 \%$ in park environments but only $13.1 \%$ in street environments (Table 4). Oslo had the largest difference between street and park environments, with Tilia spp. accounting for $45.3 \%$ of the tree population in street environments, followed by Acer platanoides with $11.6 \%$. In park environments the situation was reversed, with A. platanoides accounting for $21.2 \%$ and Tilia spp. for $17.1 \%$ (Table 4).

Among the cities which had a complete dataset of trees in street environments, Aarhus and Malmo showed the largest species diversity, where six and seven species, respectively, made up half the tree population (Table 4).

In park environments, the distribution of tree individuals in species was more even. The most notable finding was the high number of species in park environments in Aarhus (Table 4), where the nine most frequent species together only represented $31.3 \%$ of the tree population and where $68.7 \%$ of the tree stock was represented by species with an occurrence of less than $2 \%$ of the total tree population. Aarhus showed a clear difference between the tree population in street and park environments, with the eight most dominant species in street environments being present at a frequency of $2.5 \%$ or less in park environments (Table 4).

The largest species diversity index among the cities with complete dataset was found in Malmo and Aarhus with 5.15 and 4.69 respectively in street environment. The species diversity index differed greatly for those cities with incomplete dataset, 
ranging from 4.25 in street environment to 58.94 in park environment.

\section{Origin of urban trees}

Analysis of tree origins showed that the number of non-native species was higher than the number of native species in both street and park environments in all cities except Oslo and Tampere, where the number of native species were greater in street environments (Fig. 3a and c). However, the number of tree individuals belonging to native species was higher than the number of non-native individuals in all cities except Aarhus, where non-native species dominated in park environments (Fig. 3d).

The street environments in Malmo and Turku had the highest number of non-native species, while Aarhus had the highest proportion of non-native tree individuals in park environments due to the diverse tree collection at the botanical garden and high species diversity in cemeteries (Fig. $3 a$ and b). 
Table 4. Distribution of city trees across the most common species in the five Nordic cities that distinguished between trees growing in street environments and park environments.

\begin{tabular}{|c|c|c|c|c|c|c|c|c|c|c|}
\hline 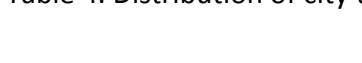 & Arhus & . & Gothe & g & Malm & & Oslo & & Turku & \\
\hline Species & Street & Park* & Street & Park & Street & Park & Street & Park & Street & Park \\
\hline Acer campestre & & & & & $2.5 \%$ & & & & & \\
\hline Acer platanoides & $10.3 \%$ & $2.1 \%$ & & & $2.6 \%$ & $3.6 \%$ & $11.6 \%$ & $21.2 \%$ & $9.1 \%$ & $10.7 \%$ \\
\hline Acer pseudoplatanus & $2.5 \%$ & & & & & $3.3 \%$ & & $5.1 \%$ & & \\
\hline Acer rubrum & & & & $3.1 \%$ & & & & & & \\
\hline Aesculus hippocastanum & $4.0 \%$ & & & $3.5 \%$ & $5.4 \%$ & $3.4 \%$ & $10.2 \%$ & $3.3 \%$ & & \\
\hline Alnus glutinosa & & & & & & & & & $2.5 \%$ & $4.2 \%$ \\
\hline Betula pendula & $4.1 \%$ & $7.0 \%$ & & & & $4.0 \%$ & $5.5 \%$ & $3.1 \%$ & $12.9 \%$ & $12.5 \%$ \\
\hline Betula pubescens & & & & & & & & $3.3 \%$ & & $2.4 \%$ \\
\hline Betula spp. & & & & $2.6 \%$ & & & $4.7 \%$ & $5.9 \%$ & & \\
\hline Betula utilis & & $2.0 \%$ & & & & & & & & \\
\hline Carpinus betulus & & $4.9 \%$ & & & $2.8 \%$ & & & & & \\
\hline Chamaecyparis lawsoniana & & $3.6 \%$ & & & & & & & & \\
\hline Crataegus monogyna & & & & & & $2.3 \%$ & & & & \\
\hline Fagus sylvatica & & $6.1 \%$ & & $3.2 \%$ & & $7.2 \%$ & & & & \\
\hline Fraxinus angustifolia & & & $3.9 \%$ & & & & & & & \\
\hline Fraxinus excelsior & $3.6 \%$ & & & $3.6 \%$ & & $4.4 \%$ & $2.8 \%$ & $2.3 \%$ & $3.3 \%$ & $2.2 \%$ \\
\hline Malus hybr. & $2.0 \%$ & & & & & & & & & \\
\hline Picea abies & & & & & & & & & & $2.6 \%$ \\
\hline Picea omorika & & & & & & & & & $2.7 \%$ & $2.9 \%$ \\
\hline Picea pungens & & & & & & & & & & $2.0 \%$ \\
\hline Pinus sy/vestris & & & & & & & & & $4.9 \%$ & $10.3 \%$ \\
\hline Platanus $x$ hispanica & $4.2 \%$ & & & & $5.0 \%$ & & & & & \\
\hline Populus canescens & & & & $3.6 \%$ & & $3.2 \%$ & & & & \\
\hline
\end{tabular}


Populus simonii

Populus tremula

Prunus avium

Prunus spp.

Prunus padus

Quercus robur

Robinia pseudoacacia

Salix alba

Sorbus aria

Sorbus aucuparia

Sorbus $x$ intermedia

Sorbus latifolia

Sorbus mougeotii

Sorbus spp.

Taxus baccata

Tilia cordata

Tilia plathyphylla

Tilia spp.
Tilia x europaea

Ulmus glabra

Ulmus minor
$7.9 \%$

$2.5 \%$

$2.3 \%$

$3.7 \%$

$5.7 \%$

$5.0 \%$

$11.3 \%$

Species with a frequency of $18.1 \%$

less than $\mathbf{2 \%}$

$8.0 \%$

$3.1 \%$

$68.7 \%$
$3.0 \%$

$5.3 \% \quad 4.2 \%$

$3.0 \% \quad 3.5 \%$

$2.3 \%$

$15.2 \% \quad 4.0 \% \quad 3.0 \%$

$2.6 \%$

$3.6 \%$

$3.4 \%$

$2.7 \%$

$9.3 \% \quad 3.8 \%$

$2.9 \%$

$3.7 \%$

$7.0 \%$

$3.3 \%$

$2.6 \%$

\begin{tabular}{cllllllll} 
& $13.9 \%$ & $19.4 \%$ & $2.9 \%$ & & $45.3 \%$ & $17.1 \%$ & & \\
& $35.5 \%$ & $10.0 \%$ & $16.5 \%$ & $2.3 \%$ & & & $16.7 \%$ & $10.8 \%$ \\
\hline $3.1 \%$ & $5.8 \%$ & & & & $4.6 \%$ & $9.3 \%$ & $5.9 \%$ & $5.0 \%$ \\
& $2.8 \%$ & & & & & & &
\end{tabular}

$19.7 \%$

$29.1 \%$

$35.9 \%$

$45.1 \%$

$21.8 \%$

$23.3 \%$

$13.1 \%$

$42,8 \%$ 


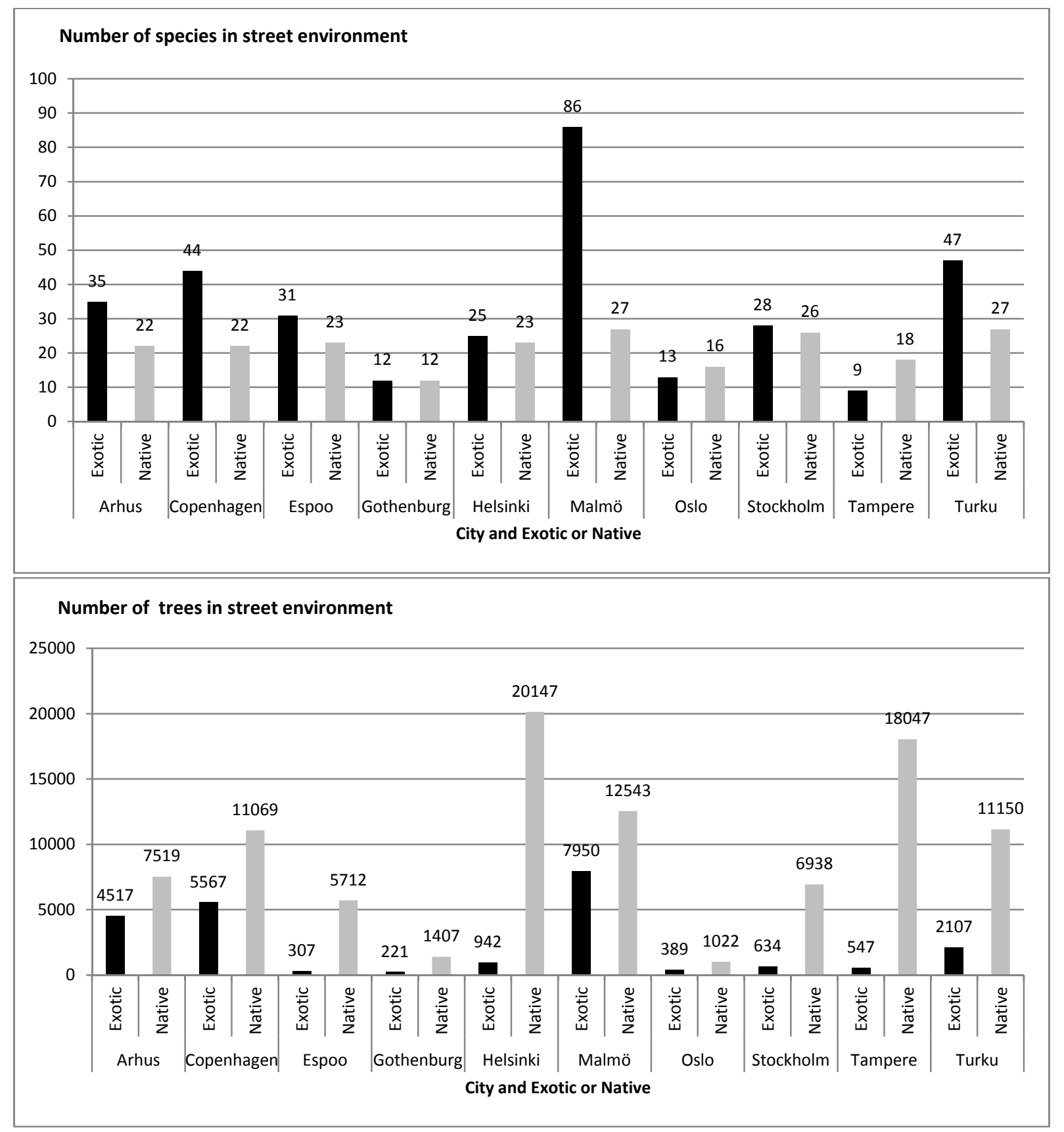




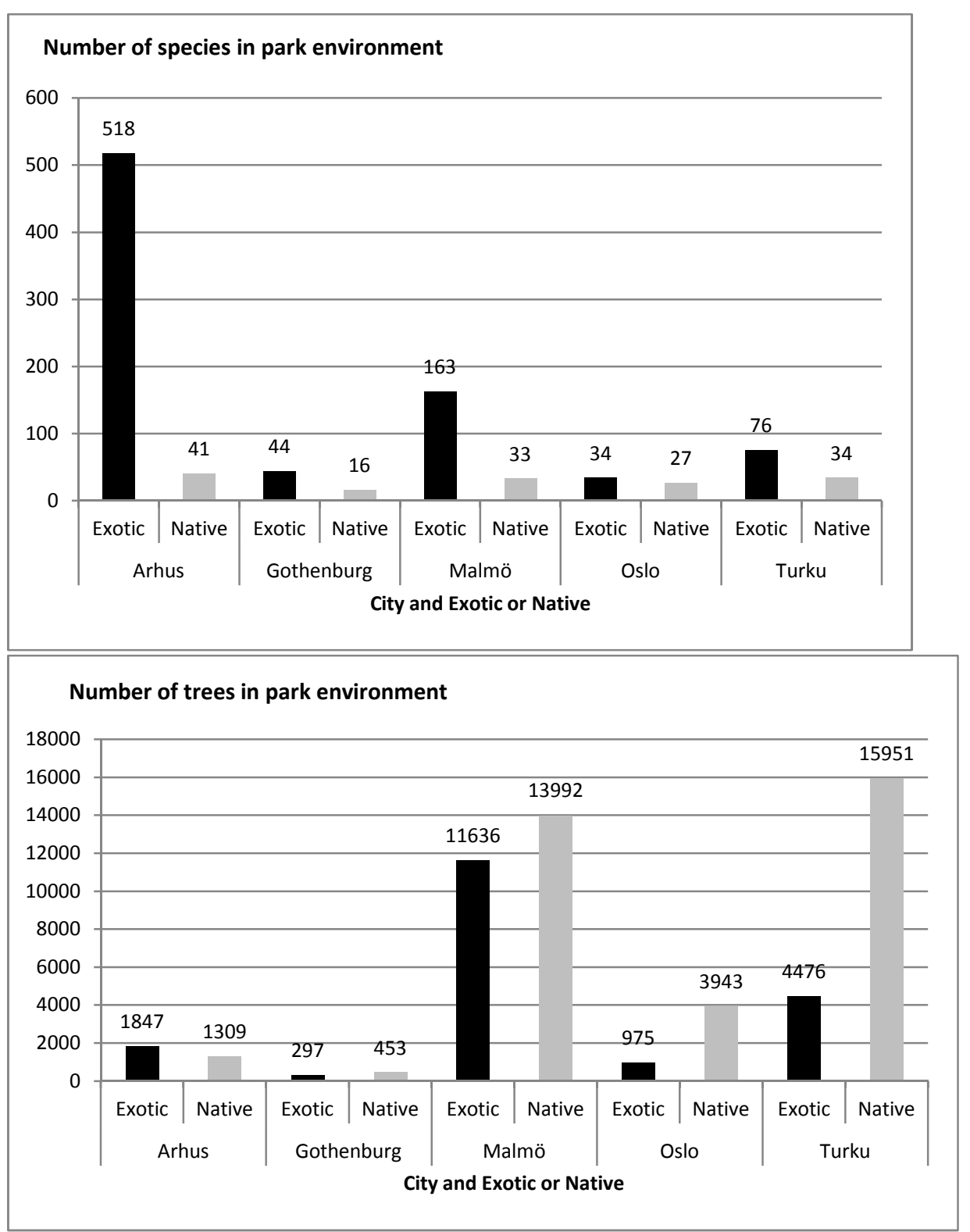

Fig. 3. (a-d) Distribution of native and non-native tree species and number of native and non-native tree individuals found in street and park environments in the 10 Nordic cities studied. 


\section{Discussion}

This study provides valuable information about the diversity and distribution of urban trees in 10 Nordic cities that can be used e.g. by policy makers when predicting potential risks facing the local urban tree population concerning outbreaks of serious pests and diseases and how well prepared a city is for future climate change. It was not possible to make direct comparisons between the cities studied, since the relevant datasets differed. Complete datasets were only available for street trees in Aarhus, Copenhagen, Helsinki, Malmo and Tampere, while data for park environments differed greatly between these cities. The databases of the remaining cities are still under development and therefore the results from these cities should be interpreted with some caution, since the species distribution could differ after a complete inventory. This is especially apparent in Table 5, where e.g. Gothenburg has a much higher species diversity index than Malmo and Copenhagen, which have complete inventories for street environments. When all trees in Gothenburg are included in the database the results will probably show a different index. Nevertheless, the incomplete datasets provided valuable information about the diversity of species and genera, the difference in diversity between trees in street and park environments and the relative proportions of native and non-native tree species. It is important to visualise such information at an early stage in order to start a debate concerning future risks the local urban tree population might face regarding pests and diseases and predicted climate change.

One of the existing recommendations regarding diversity is that no species in a city should exceed more than $10 \%$ of the total tree population (Grey and Deneke, 1986; Smiley et al., 1986; Santamour, 1990; Miller and Miller, 1991). Only Malmo complied with this recommendation in terms of entire tree population, irrespective of site situation (Table 3). In contrast, Helsinki had Tilia $\times$ europea as the most common urban tree, representing $44.3 \%$ of the total tree population (Table 3 ). The urban tree population of Helsinki is thus highly susceptible to outbreaks of pests or diseases of Tilia $\times$ europea (Tello et al., 2005; Raupp et al., 2006). This also applies to many Nordic cities, since Tilia $\times$ europaea was one of the most common tree species in five of the 10 cities studied here (Table 3). The Oslo tree inventory contained high numbers of Tilia spp. without further species classification. However, based on earlier studies by Pauleit et al. (2002), it can be concluded that a high proportion of these are probably Tilia $\times b$ europaea. Moreover, in the comparison between street and park environments (only possible in fiveof the 10 cities), no city complied with the recommendation that no species should account for more than $10 \%$ of the tree population in street environments, although this recommendation was met for park environments in Aarhus and Malmo (Table 4). This illustrates the need for knowledge and experience of a greater catalogue of suitable species, in particular for street environments. While the current recommendations on species diversity with different percentage mixtures of species and genera are more or less based on theoretical grounds, they act as important guidelines and arguments in planning higher diversity. However, today there is no clear knowledge and experience available about sustainable levels of diversity for an urban tree population. The maximum inclusion level of $10 \%$ is recommended by several authors (Grey and Deneke, 1986; Smiley et al., 1986; Santamour, 1990; Miller and Miller, 1991), but is rather high, and the recommendation from Barker (1975) and Moll (1989) that no species in a tree population should exceed $5 \%$ is perhaps more sustainable. No city in the present study could achieve the latter level.

Although the recommendations cited are important in the argument for greater diversity, an important consideration may be overlooked in the rush to diversify. Simply ordering new tree species and genotypes that are untested for the region is not the right course where adaptability and longevity of species in stressful urban habitats must weigh heavily in the selection (Raupp et al., 2006). Poor or incorrect choices may result in increased mortality, reduced lifespan of trees and ultimately greater costs when failed or failing trees must be removed or replaced (Richards, 1982/1983; Tello et al., 2005; Raupp et al., 2006).

In general, there were fewer species accounting for the majority of the tree population in street environments compared with park environments, confirming earlier studies (Sabo et al., 2005). This might reflect the situation that a large number of species can be grown in the favourable conditions often found in urban woodlands and parklands, but that identification of species that can withstand the 
challenging conditions in street environments and at other paved sites is much more difficult (Pauleit, 2003). Based on this, the use of a small number of species known to survive in these situations is understandable.

Table 5. Species diversity index $=[$ species count/tree count $] \times$ 1000 distinguishing between street and park environments.

\begin{tabular}{llll}
\hline City & Street & Park & Total \\
\hline Arhus $^{\mathrm{a}}$ & 4.69 & 165.53 & 3.67 \\
Copenhagen $^{\mathrm{a}}$ & 3.64 & - & 3.64 \\
Espoo $^{\mathrm{b}}$ & 8.87 & - & 8.87 \\
Gothenburg $^{\mathrm{b}}$ & 11.14 & 58.94 & 20.64 \\
Helsinki $^{\mathrm{a}}$ & 2.15 & - & 2.15 \\
Malmo $^{\mathrm{a}}$ & 5.15 & 7.25 & 4.19 \\
Oslo $^{\mathrm{b}}$ & 9.27 & 7.74 & 5.81 \\
Stockholm $^{\mathrm{b}}$ & 4.25 & - & 4.25 \\
Tampere $^{\mathrm{a}}$ & 1.30 & - & 1.30 \\
Turku $^{\mathrm{b}}$ & 5.32 & 5.19 & 3.28 \\
\hline
\end{tabular}

a Cities for which an almost complete inventory exists

${ }^{b}$ Cities where limited parts of the urban tree population are inventoried

Furthermore, much of the information concerning nontraditional tree species that can tolerate street environments and other paved site situations, especially for the Nordic region, is very limited (Sjoman and Nielsen, 2010). Much of the sitespecific information available has been obtained in other parts of the world, which makes it difficult to interpret these experiences for the Scandinavian region. However, regional experiences derived from local urban tree databases can act as a knowledge base, with regional evaluations of trees in e.g. street environments providing local and contextual information and guidance on species growth and performance at the specific site. Of special interest are the species that are currently used only in limited numbers and, after positive evaluation, could be used more frequently. For example, 35.9\% of the total tree population in street environments in Malmo comprised species with less than $2 \%$ occurrence (Table 4). Here, many species have shown a longstanding tolerance to the local site situation and their use could be extended to other sites. For park environments, local arboreta and botanical gardens can act as local knowledge bases providing inspiration for greater species diversity in public parks. In Aarhus, the local botanical garden, which has included its tree population in the city's urban tree database, records a large number of species with long and sustainable development (Table 4). However, in order to find reliable guidance in this direction, data on e.g. age and DBH (diameter at breast height) provide important information in determining the long-term tolerance of rare species to the local site situation. Such data were only available for one of the 10 cities studied here and were hence not included in the analysis. However, collecting these data exclusively for rare tree species could give fast and reliable guidance on species that have the potential for further introduction into the local urban tree population.

Although this study indicates a high diversity of species in park environments, for example in Aarhus and Malmo, this can provide a somewhat distorted picture, since the high diversity is located in a restricted area of the city or a species is located in one particular place. In the case of Aarhus, the botanical garden in the city significantly increases the number of species in park environments in the city, but this is linked to a specific place, whereas other parks and public woodlands can have much less diversity. In Malmo, some species are associated with a specific area. For example, Fagus sylvatica represents $7.2 \%$ of the total tree population in park environments (Table 4), but is more or less restricted to one park, Pildamms Park, where it dominates almost totally (A. Mattsson, personal communication, 2010). Information on the distribution of species in the cities was not available for this study, but in order to develop a healthy and sustainable urban tree population, a diversity of species must be evenly distributed throughout the city.

Concerning species origin, great numbers of nonnative species occurred in all the cities studied, especially in street environments (Fig. 3). However, although there were high proportions of non-native species, the majority of the tree population consisted of native tree species. Aarhus was an exception in park environments due to its botanical garden's large tree collection, with many non-native tree species (Fig. 3). At present, there is an intensive discussion on whether it is appropriate to recommend non-native tree species in public plantations, with the fear of these species escaping and negatively affecting native species and ecosystems being the main counter-argument (Parker et al., 1999; Alien Plant Working Group, 2010; Hitchmough, 2011). The time during which a species has been cultivated in an area combined with the number of individuals of the species 
present in a region determines the risk of that species escaping from cultivation into the natural environment and becoming a potential invasive species (Chytry' et al., 2008; Py̌sek et al., 2009). Since native species dominated the urban tree stock in the cities studied, this might not be a current threat (Fig. 3b and d). However, due to outbreaks of pests and diseases in many of these overused native trees the use of non-native species will increase in the near future, so it is reasonable to expect that more non-native species will escape from cultivation into the natural environment in the future. Much more research is needed to provide tools to predict the interactions of non-native species with native ecosystems and thus help with early identification of potentially invasive species.

Furthermore, restricting the urban tree population to native tree species is scarcely practicable, especially in street environments. From the perspective of the northern parts of Central Europe and adjoining milder parts of Northern Europe, it is unlikely that the species-poor native dendroflora can contribute a large range of tree species with extended tolerance to the environmental stresses characterising streets and other paved sites (Duhme and Pauleit, 2000). Other regions with a comparable climate but a richer

\section{References}

Akbari, H., Pomerantz, M., Taha, H., 2001. Cool surfaces and shade trees to reduce energy use and improve air quality in urban areas. Solar Energy 70 (3), 295-310.

Alden, B., Ryman, S., 2009. Cultivated Plant Names (Vara Kulturvaxters Namn). Formas, Stockholm (in Swedish).

Alien Plant Working Group, 2010. Weeds Gone wild: alien plant invaders of natural areas. Plant conservation Alliance. Retrieved May 15, 2011 from http://www.nps.gov/plants/alien/bkgd.htm.

Barker, P., 1975. Ordinance control of street trees. Journal of Arboriculture 1, 121-215.

Bassuk, N., Deanna, F.C., Marranca, B.Z., Barb, N., 2009. Recommended Urban Trees: Site Assessment and Tree Selection for Stress Tolerance. Urban Horticulture Institute, Cornell University, Ithaca, New York.

Becket, K.P., Freer-Smith, P., Taylor, G., 2000. Effective tree species for local airquality management. Journal of Arboriculture 26, 12-19. dendroflora may have the potential to contribute new tree species and genera that are equally or even better adapted to the growing conditions at urban paved sites (Takhtajan, 1986; Breckle, 2002; Roloff et al., 2009; Sjoman and Richnau, 2009). This will be even more important in view of future climate change, with predicted increases in average temperatures and more frequent heat waves and periods of drought during summer (IPCC, 2007).

The concluding recommendation from this study regarding greater diversity of genera and species for the Nordic region is to exploit local experiences of rare species from local urban tree databases. After appropriate evaluation, urban tree planners can evaluate these rare species in larger numbers for e.g. street environments, where the need is greatest. Saying this, it is important to collect additional data such as age, dbh and height of the trees, which will give a much more detailed guidance of which species that could be further recommended for e.g. street environments. The use of non-native tree species in public plantations is inevitable, so special interest and research should be devoted to identification of species and strategies which could pose a threat of invasiveness and negative impact on native species and ecosystems.

Breckle, S.W., 2002. Walter's Vegetation of the World, 4th edition. Springer, $527 \mathrm{pp}$.

Chytry' , M., Jaro`sik, V., Py̌sek, P., Hajek, O., Knollova, I., Tichy' , L., Danihelka, J., 2008. Separating habitat invasibility by alien plants from the actual level of invasion. Ecology 89 (6), 15411553.

Duhme, F., Pauleit, S., 2000. The dendrofloristic richness of SE-Europe, a phenomenal treasure for urban plantings. Mitteilungen aus der Biologischen Bundesanstalt fur Land- und Forstwirtschaft BerlinDahlem 370, 23-39.

Frank, S., Waters, G., Beer, R., May, P., 2006. An analysis of the street tree population of greater Melbourne at the beginning of the 21st century. Arboriculture and Urban Forestry 32 (4), 155-163.

Grey, G.W, Deneke, F.J., 1986. Urban Forestry, 2nd edition. Wiley, New York. Hitchmough, J.D., 2011. Exotic plants and plantings in the sustainable, design urban landscape. Landscape and Urban Planning 100, 380-382. 
IPCC, Intergovernmental Panel on Climate Change, 2007. IPCC Fourth Assessment Report (AR 4).

Jim, C.Y., Liu, H.T., 2001. Species diversity of three major urban forest types in Guangzhou City, China. Forest Ecology and Management 146, 99114.

King, V.J., Davis, C., 2007. A case study of urban heat island in the Carolinas. Environmental Hazards 7, 353-359.

Maco, S.E., McPherson, E.G., 2003. A practical approach to assessing structure, function and value of street tree population in small communities. Journal of Arboriculture 29, 84-97.

McPherson, E.G, Nowak, D., Heisler, G., Grimmond, S., Souch, C., Grant, R., Rowntree, R., 1997. Quantifying urban forest structure, function and value: the Chicago Urban Forest Climate Project. Urban Ecosystems 1, 49-61.

Miller, R.H., Miller, R.W., 1991. Planting survival of selected street tree taxa. Journal of Arboriculture 17, 185-191.

Moll, G., 1989. Improving the health of the urban forest. In: Moll, G., Ebenreck, S. (Eds.), A Resource Guide for Urban and Community Forests. Island Press, Washington, pp. 119-130.

Mossberg, B., Stenberg, L., 2003. The New Nordic Flora. Wahlstrom and Widstrand, Stockholm (in Swedish).

Negandra, H., Gopal, D., 2010. Street tree in Bangalore: density, diversity, composition and distribution. Urban Forestry and Urban Greening 9, 129-137.

Nowak, D., Crane, D., Stevens, J., 2006. Air pollution removal by urban trees and shrubs in the United States. Urban Forestry and Urban Greening 4, 115-123.

Parker, I.M., Simberloff, D., Lonsdale, W.M., Goodell, K., Wonham, M., Kareiva, P.M., Williamson, M.H., Von Holle, B., Moyle, P.B., Byers, J.E., Goldwasser, L., 1999. Impact: towards a framework for understanding the ecological effects of invaders. Biological Invasion 1, 3-19.

Pauleit, S., 2003. Urban street tree plantings: identifying the key requirements. Proceedings of the Institute of Civil Engineers-Municipal Engineers 156 (1), 43-50.

Pauleit, S., Jones, N., Garcis-Martin, G., GarciaValdecantos, J.L., Riviere, L.M., Vidal- Beaudet, L., Bodson, M., Randrup, T.B., 2002. Tree establishment practise in towns and cities - result from a European survey. Urban Forestry \& Urban Greening 1 (2), 83-96.

Py`sek, P., Krivanek, M., Jaro`sik, V., 2009. Planting intensity, residence time, and species traits determine invasion success of alien woody species. Ecology 90 (10), 2734-2744.

Raupp, M.J., Cumming, M.J., Raupp, E.C., 2006. Street tree diversity in eastern North America and its potential for tree loss to exotic borers. Arboriculture \& Urban Forestry 32 (6), 297-304.

Richards, N.A., 1983. Diversity and stability in a street tree population. Urban Ecology 7, 159-171.

Roloff, A., Korn, S., Gillner, S., 2009. The climatespecies-matrix to select tree species for urban habitats considering climate change. Urban Forestry and Urban Greening 8, 295-308.

Sabo, A., Benedikz, T., Randrup, T.B., 2003. Selection of trees for urban forestry in the Nordic countries. Urban Forestry and Urban Greening 2, 101-114.

Sabo, A., Zelimir, B., Ducatillion, C., Hatzistathis, A., Lagerstrom, T., Supuka, J., Garcis- Valdecantos, J.L., Rego, F., Slycken, J., 2005. The selection of plant materials for street trees, park trees and urban woodlands. In: Konijnendijk, C.C., Nilsson, K., Randrup, T.B., Schipperijn, J. (Eds.), Urban Forests and Trees. Springer, Berlin, pp. 257-280.

Sanders, R.A., 1981. Diversity in the street trees of Syracuse, New York. Urban Ecology 5, 33-43.

Santamour, F.S., 1990. Trees for urban planting: diversity, uniformity and common sense. In: Proceedings of the 7th Conference of the Metropolitan Tree Improvement Alliance, vol. 7, pp. 57-65.

SCB, 2010. Swedish Office for National Statistics. Retrieved August 31, 2010 from http://www.scb.se/statistik/MI/MI0810/2005A01/ mi0810tab5.xis.

Sieghardt, M., Mursch-Radlgruber, E., Paoletti Couenberg, E., Dimitrakopoulus, A., Rego, F., Hatzistatthis, A., Randrup, T., 2005. The abiotic urban environment: impact of urban growing conditions on urban vegetation. In: Konijnendijk, C.C., Nilsson, K., Randrup, T.B., Schipperijn, J. (Eds.), Urban Forests and Trees. Springer, Berlin, pp. 281323.

Sjoman, H., Nielsen, A.B., 2010. Selecting trees for urban paved sites in Scandinavia - a review of information on stress tolerance and its relation to the requirements of tree planners. Urban Forestry and Urban Greening 9, 281-293. 
Sjoman, H., Richnau, G., 2009. North-east Romania as a future source of trees for urban paved environments in north-west Europe. Journal of Plant Development 16, 37-46.

Smiley, E.T., Kielbaso, J.J., Proffer, T.J., 1986. Maple disease epidemic in southeastern Michigan. Journal of Arboriculture 12 (5), 126-128.

SSB, 2010. Norwegian Office for National Statistics. Retrieved August 31, 2010 from http://www.ssb.no/beftett en/tab-2009-06-16-01en.html.

STAT, 2010. Finish Office for National Statistics. Retrieved August 31, 2010 from: http://www.stat.fi/tup/suoluk/suoluk vaesto sv.html\#storsta.

Statistikbanken, 2010. Danish Office for National Statistics. Retrieved August 31, 2010 from: http://www.statistikbanken.dk/statbank5a/SelectV arVal/Define.asp? Maintable=BEF4\&PLanguage $=0$.

Sun, W.Q., 1992. Quantifying species diversity of streetside trees in our cities. Journal of Arboriculture 18 (2), 91-93.

Takhtajan, A., 1986. Floristic of the World. University of California Press, Berkeley, CA.

Tello, M.-L., Tomalak, M., Siwecki, R., Gaper, J., Motta, E., Mateo-Sagasta, E., 2005. Biotic urban growing condition - threats, pests and diseases. In: Konijnendijk, C.C., Nilsson, K., Randrup, T.B., Schipperijn, J. (Eds.), Urban Forests and Trees. Springer, Berlin, pp. 325-365.

Tyrvainen, L., Makinen, L., Schipperijn, J., 2007. Tools for mapping social values for urban woodlands and of other green spaces. Landscape and Urban Planning 79(1), 5-19. 